\title{
レーザー除染におけるアブレーション過程のシミュレーション
}

\author{
古河裕之, S. I. ANISIMOV *,†, 西原 功修*, 今崎一夫, 藤田 雅之, 船橋 達** \\ 二村 嘉明**, 坂岸 光二**, 中西 友和 $* *$, 本田 茂男 $* *$, 山中 千代衛 \\ （財）レーザー技術総合研究所（† 565-0871 大阪府吹田市山田丘 2-6） \\ *大阪大学レーザー核融合研究センター（† 565-0871 大阪府吹田市山田丘 2-6） \\ **（株）アトックス（テ277-0861 千葉県柏市高田 1408 番地）
}

\section{Simulation of Ablation Process on Laser Cleaning}

\author{
Hiroyuki FURUKAWA, S. I. ANISIMOV, ${ }^{*}$, Katsunobu NISHIHARA* \\ Kazuo IMASAKI, Masayuki FUJITA, Satoru FUNAHASHI** \\ Yoshiaki FUTAMURA**, Koji SAKAGISHI**, Tomokazu NAKANISHI** \\ Shigeo HONDA**, and Chiyoe YAMANAKA \\ Institute for Laser Technology, 2-6 Yamada-oka, Suita, Osaka 565-0871 \\ *Institute of Laser Engineering, 2-6 Yamada-oka, Suita, Osaka 565-0871 \\ **Atox, 1408 Takada, Kashiwa, Chiba 277-0861
}

(Received October 7, 1997)

\begin{abstract}
Theoretical estimations on laser cleanings have been performed by simulations. Basic equations are the equation of thermal conduction, the absorption of laser energy, boundary conditions of melting and evaporation. Simulations have been performed for the case of 2-layers, basic material is SUS304 and surface pollutant is $\mathrm{Fe}_{3} \mathrm{O}_{4}$. Simulation results were in good agreements with experiments at the wide range of irradiated laser energy densities.
\end{abstract}

Key Words: Simulation, Laser cleaning, Melting, Evaporation, $\mathrm{Fe}_{3} \mathrm{O}_{4}$

\section{1. 緒 論}

近年, 原子力施設の高経年化に伴い, 施設の更新が切実 な問題となっている。これらの施設は放射能で污染され ている可能性があるため,その廃棄処理は非常に入念に行 わなければならない。しかし, 污染物表面に付着した放射 性物質のみを除去してしまえば,廃棄処理の効率は格段に 向上する。よって, 污染物表面に付着した放射性物質を如 何にして効率よく除去するかは, 原子力施設, ひいては電 力の安定な供給に関して非常に重要な課題である.

レーザー除染1-3)の場合, 遠隔操作が容易であり, 作業者 にとって極めて安全に除染を行える可能性がある。本研 究では, 原子力施設内の污染物表面にレーザーを照射し, レーザーアブレーションにより污染物表面に付着した放 射性物質のみを融解, 蒸発し除去する。 そのためのレー ザーのパルス幅, 波長, 強度等の最適化をシミュレーショ ンにより行うことを目的とする。

\section{2. 除染率の簡単な式表示}

放射性物質の相対減少量を求める．母材の表面に厚さd の放射性物質が一様に付着している場合を考える。母材 の内部は, 厚さ $L$ 程度まで放射化されており，その密度は線 形的に減少している,とする。一度除去した物質は再付着 しない, 自己吸収率も0であるとすると, 除去された放射性 物質の量 $s$ 次のように与えられる.

$$
\begin{aligned}
s & =A z & & z<d \\
& =A d+B(z-d)\left(1-\frac{z-d}{2 L}\right) & & d \leq z<d+L
\end{aligned}
$$

相対除染率は次のように与えられる。

$$
R=\frac{s}{A d+B L / 2}
$$

$A$ は, 表面に付着した放射性物質層において線源原子数密 度と放射率を掛けたもの, Bは, 放射性物質と母材との界面 において線源原子数密度と放射率を掛けたもの,である. $z$ は, 蒸発した厚さである. $A, B, d, L$ O值は入力值として与 えることができる.ゆえに, どの程度の厚さの部分が蒸発 したか, を知れば除去された放射性物質の量を求めること

\footnotetext{
† Present address; Landau Institute for Theoret. Phys., 117940 Moscow, Kosyginast.2, Russia
} 


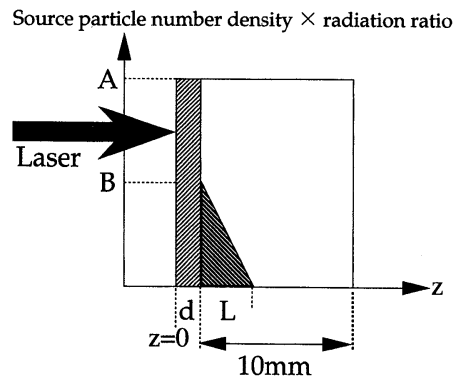

Fig.1 Simple model for laser cleaning ratio.

ができる。

\section{3. 実験結果}

原子力施設の除染のための予備実験として,SUS304の表 面に酸化被膜等を作り,レーザーで除染する実験を行っ た．試料は次のようにして作成した。試料の温度を $600^{\circ} \mathrm{C}$, または $800^{\circ} \mathrm{Cに}$ に保ちながら, 大気中においてガスバーナーで 1 時間加熱し, SUS304の表面に1 $1 \mu \mathrm{m}$ 程度の酸化被膜等を 作った。用いたレーザーはNd:YAGレーザー，波長は 1064nmである. Fig.2に,レーザーパルスのパラメーターを 示す．用いたレーザーはモードロックレーザーで, ミクロ パルス幅20ps, ミクロパルス間隔を $11.2 \mathrm{~ns}$, マクロパルス幅

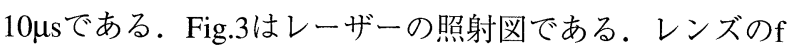
ナンバーは $250 \mathrm{~mm}$ である。本研究ではレンズと試料の距 離を, 250, 255, 260, 265, 270, 275mm と変えてレーザーを照 射し,SUS304の表面の除去の様子を調べた．除去した深さ は探針法で測定した。

Fig.4は, 実験により求めた除去体積とレーザーエネル ギー密度の関係である．横軸は照射されたレーザーのエ ネルギー密度, 縦軸は単位エネルギー当たりの除去体積で ある. Fig.4から, 単位エネルギー当たりの除去体積は, レー ザーのエネルギー密度に逆比例していることがわかる. 本実験では, $10 \mu \mathrm{s}$ のクロパルス 1 つのことを 1 shot と数え

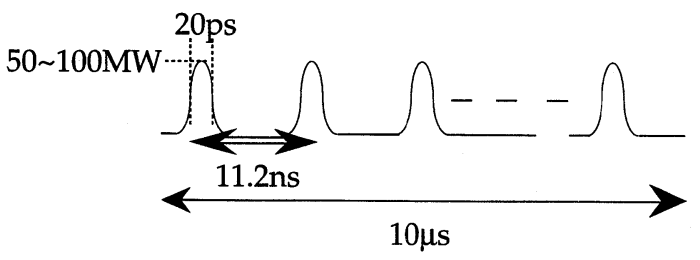

Fig.2 Parameters of laser.

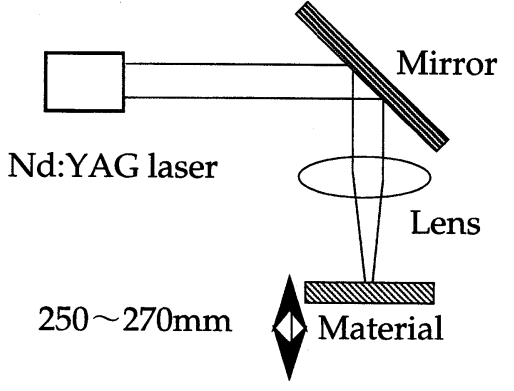

Fig.3 Schematic diagram of laser irradiation.

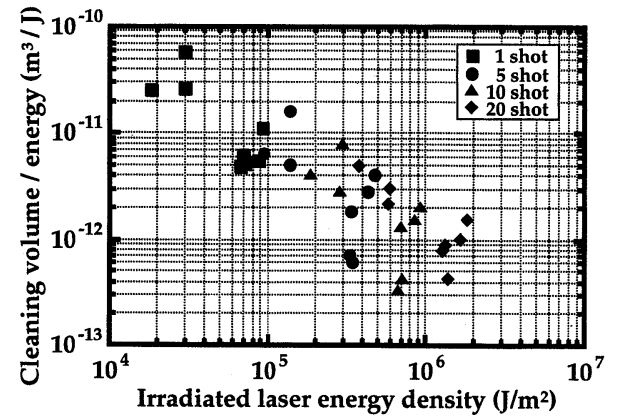

Fig.4 Cleaning volume per unit energy as irradiated laser energy density obtained by experiments.

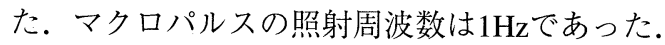

$$
\text { 4. シミュレーションによる解析 }{ }^{4)}
$$

4.1 基礎方程式

上記の実験結果を理論的に解析するために, 厚み方向の みの1次元のシミュレーションを行った。 熱伝導方程式を 解いて温度分布を決定し, 融解, 蒸発の効果も取り入れて いる. Fig.5に, シミュレーションの際のgeometryを表す.

Fig.5の上部の黒い部分は, 厚さ $1 \mu \mathrm{m}$ 程度の黒錆, 下部は母 材であるSUS304を表す。

以下に, 基礎方程式4)を記す。

$\bigcirc$ 熱伝旗方程式

$$
\begin{aligned}
& \rho_{\mathrm{s}} c_{\mathrm{s}} \frac{\partial T}{\partial t}=\frac{\partial}{\partial z}\left(\kappa_{\mathrm{s}} \frac{\partial T}{\partial z}\right)+Q(z, t) \\
& Z_{\mathrm{m}}(t)<z<\infty \\
& \rho_{\mathrm{l}} c_{1} \frac{\partial T}{\partial t}=\frac{\partial}{\partial z}\left(\kappa_{1} \frac{\partial T}{\partial z}\right)+Q(z, t) \\
& Z_{\mathrm{v}}(t)<z<Z_{\mathrm{m}}(t)
\end{aligned}
$$

ここで, $Q$ は単位体積, 単位時間当たりの発熱量, $c$ は比熱, $k$ は熱伝導率である。添字のs, 1 はそれぞれ固体, 液体を表 す. $Z_{\mathrm{m}}$ は固体と液体の境界点, $Z_{\mathrm{v}}$ は液体と気体の境界点を 表す.

○発熱条件 (レーザー光の吸収)

$$
Q(z, t)=I(t) \frac{1-R}{\delta} \exp \left\{-\left(z-Z_{\mathrm{v}}(t)\right) / \delta\right\}
$$

ここで, $I(t)$ はレーザー強度, $R$ は反射率, $\delta$ 表皮厚さであ る.

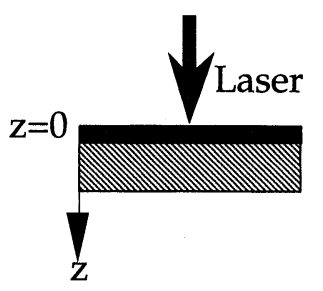

Fig.5 Geometry of simulations. 
○境界条件

$$
\begin{aligned}
& L_{\mathrm{m}} \frac{\partial Z_{\mathrm{m}}(t)}{\partial t}=\left.\kappa_{\mathrm{s}} \frac{\partial T}{\partial z}\right|_{z=z_{\mathrm{m}}}-\left.\kappa_{1} \frac{\partial T}{\partial z}\right|_{z=z_{\mathrm{m}}} \\
& L_{\mathrm{v}} \frac{\partial Z_{\mathrm{v}}(t)}{\partial t}=\left.\kappa_{1} \frac{\partial T}{\partial z}\right|_{z=z_{\mathrm{v}}}
\end{aligned}
$$

ここで, $L_{\mathrm{m}}$ は融解熱, $L_{\mathrm{v}}$ は気化熱である.

$\bigcirc Z_{\mathrm{m}}$ と $Z_{\mathrm{v}}$ の運動方程式

$$
\begin{gathered}
\frac{\partial}{\partial t} Z_{\mathrm{m}}(t)=V_{\mathrm{m}} c_{\mathrm{s}}\left(T_{\mathrm{f}}-T_{\mathrm{m}}\right) / L_{\mathrm{m}} \\
T_{\mathrm{f}}=T\left(Z_{\mathrm{m}}(t)\right) \\
\frac{\partial}{\partial t} Z_{v}(t)=V_{0} \exp \left(-U / T_{v}\right) \\
T_{v}=T\left(Z_{v}(t)\right)
\end{gathered}
$$

ここで, $T_{\mathrm{m}}$ は融点である. $V_{\mathrm{m}}, V_{0}$ は音速のオーダーの定数 で,物質により決まる4). Fig.6に, シミュレーションコード のフローチャートを示す.

\section{2 シミュレーション結果及び考察}

以上の基礎方程式を用いてシミュレーションを行っ た.シミュレーションでは, レーザーの波長を $1 \mu \mathrm{m}$, ミクロ パルス波形はガウシアン, ミクロパルス幅は $20 \mathrm{ps}$, ミクパ ルス間隔を10ns, マクロパルス幅を $10 \mu \mathrm{s}$ とした。また, 黒錆 の厚さを $1 \mu \mathrm{m}$, 母材のSUS304の厚さを $99 \mu \mathrm{m}$ と, 2 層の場 合のシミュレーションを行った。黒錆の厳密な気化熱は, 未だ測定されていない. 本研究では, 黒錆の実効的な気化 熱として, $83.9 \mathrm{~kJ} / \mathrm{mol}, 28.0 \mathrm{~kJ} / \mathrm{mol}$ の通りの場合についてシ ミュレーションした. $83.9 \mathrm{~kJ} / \mathrm{mol}$ というのは,鉄の気化熱で ある5)。黑錆及びSUS304が融解, 蒸発する厚さを時間の関 数として求め, 単位エネルギー当たりの除去体積を入射し

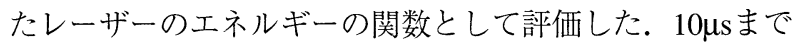
シミュレーションを行った.シミュレーションにより求 めた, 単位エネルギー当たりの除去体積をFig.7に示す.

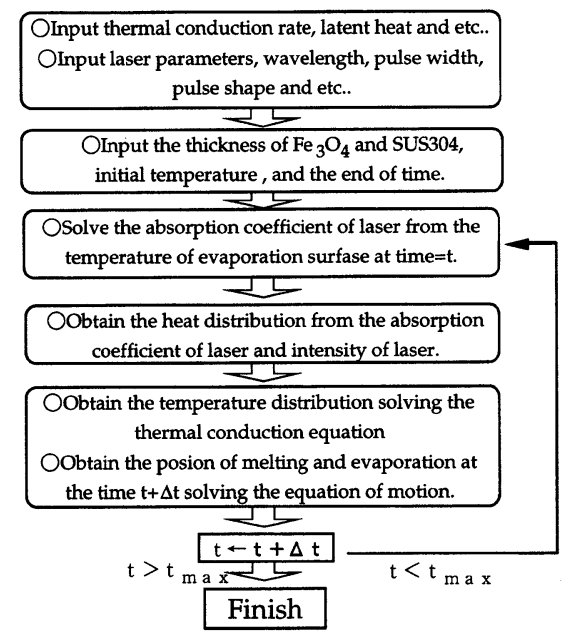

Fig.6 Flow chart of simulation code.
Fig.7からわかるように, 83.9kJ/mol, 28.0kJ/molの2通りの場 合で,大きく異なった結果を示している. $28.0 \mathrm{~kJ} / \mathrm{mol}$ の場合 のシミュレーション結果は, レーザーの照射エネルギー密 度が $2 \times 10^{4} \mathrm{~J} / \mathrm{m}^{2} \sim 10^{6} \mathrm{~J} / \mathrm{m}^{2}$ 辺りの領域で, 実験結果と非常に 良い一致を示している，以降本論文では, 黒錆の実効的な 気化熱を $28.0 \mathrm{~kJ} / \mathrm{mol}$ とした場合について, 議論を行う。

Fig.8は, 黒錆及びSUS304が融解, 蒸発する厚さを, 入射 したレーザーのエネルギーの関数として示したものであ る. Fig.からわかるように,レーザーのエネルギーが $2 \times$ $10^{4} \mathrm{~J} / \mathrm{m}^{2}$ を超えた当たりから, 急激に融解, 蒸発が起こって いる. また $2 \times 10^{4} \mathrm{~J} / \mathrm{m}^{2} \sim 10^{6} \mathrm{~J} / \mathrm{m}^{2}$ 辺りの領域では, 黒錆のみ が蒸発しており, 融解現象はSUS304内部まで進んでいる. $10^{6} \mathrm{~J} / \mathrm{m}^{2}$ 超えた当たりからSUS304も蒸発し始めており, 2 $\times 10^{6} \mathrm{~J} / \mathrm{m}^{2}$ を超えた当たりからは, 液体部分は殆ど存在しな くなっている。またFig.8から, 蒸発現象は融解現象に比 ベ,より閾值依存性の強い現象であることが示唆される.

幾つかの典型的なエネルギー密度の場合を例にとり, 融 解と蒸発の時間発展を議論する. Fig.8 (a) はエネルギー密 度が $2 \times 10^{4} \mathrm{~J} / \mathrm{m}^{2}$ の場合, (b) はエネルギー密度が $10^{6} \mathrm{~J} / \mathrm{m}^{2}$ の 場合である. $2 \times 10^{4} \mathrm{~J} / \mathrm{m}^{2}$ は蒸発が起こり始める闇值付近の エネルギー密度で, 単位エネルギー当たりの除去体積が最 も大きいところである。 $2 \times 10^{4} \mathrm{~J} / \mathrm{m}^{2}$ の場合. $8.7 \mu \mathrm{s}$ 程度まで は融解も蒸発も起こらず, その後急激に融解と蒸発が起こ り, 黒錆の蒸発が終了してからも, 融解は継続している. また $9 \mu \mathrm{s}$ 程度の時に, 一度液体になった部分が, 再び一部固 体化している様子が示されている. $10^{6} \mathrm{~J} / \mathrm{m}^{2}$ の場合, $0.2 \mu \mathrm{s}$ 程 度までに黒錆の蒸発が終了しており,その後蒸発は見られ

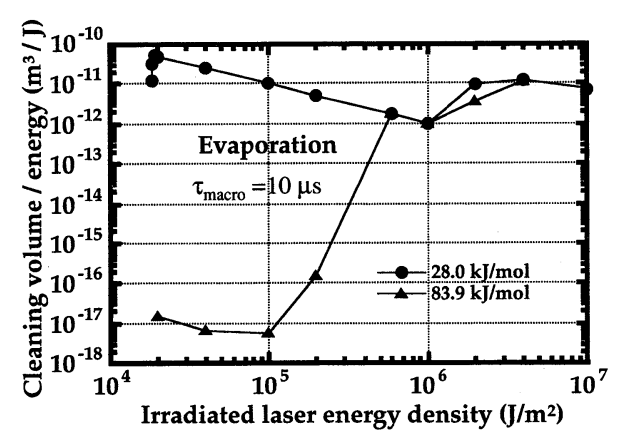

Fig.7 Cleaning volume per unit energy as irradiated laser energy density for the case $L \mathrm{v}=28.0 \mathrm{~kJ} / \mathrm{mol}$ and $L \mathrm{v}$ $=83.9 \mathrm{~kJ} / \mathrm{mol}$.

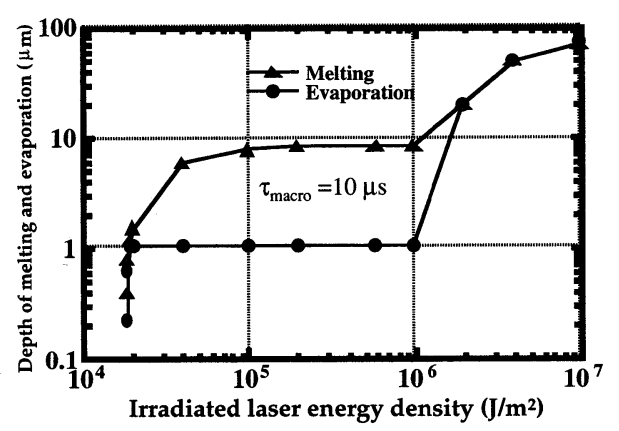

Fig.8 Depth of melting and evaporation of $\mathrm{Fe}_{3} \mathrm{O}_{4}(1 \mu \mathrm{m}$ thickness) and SUS304. 
なかった．黑錆の蒸発が終了してからも融解は継続して おり，母材の部分まで融解が進んでいる。

Fig.9は, エネルギー密度が $2 \times 10^{6} \mathrm{~J} / \mathrm{m}^{2}$ の場合の融解と蒸 発の時間発展である. Fig.8の場合と異なり,母材も蒸発し ていることがわかる。しかも蒸発の仕方が4段階ほどに分 かれており，6 4 s以降殆ど液体部分は存在していない。工ネ ルギー密度を $2 \times 10^{6} \mathrm{~J} / \mathrm{m}^{2}$ に保ち, マクロパルス幅を $20 \mu \mathrm{s} に$ した場合の, 融解と蒸発の時間発展をFig.11に示す。つま り照射強度は, Fig.10の場合の1/2であり, Fig.9 (b) の場合と 同じである。単位エネルギー当たりの除去体積は, $5.006 \times$ $10^{-13} \mathrm{~m}^{3} / \mathrm{J}$ である. Fig.11の結果は, Fig.8 (b)の場合の結果を そのまま20usまで延長したものとほぼ等しい。母材の蒸発 は見られない。このように閾值付近では, エネルギー密度 だけでなく,照射強度に対する依存性も非常に強くなる. また照射強度をFig.10の場合と同じにして,マクロパルス 幅 $5 \mu \mathrm{s}$ 時の単位エネルギー当たりの除去体積を求めると, $3.972 \times 10^{-12} \mathrm{~m}^{3} / \mathrm{J}$ となる。この場合, エネルギー密度は $10^{6}$ $\mathrm{J} / \mathrm{m}^{2}$ である. Fig.7の気化熱を $28.0 \mathrm{~kJ} / \mathrm{mol}$ とした場合のデー 夕に, 上記の結果を重ねると, Fig.12のようになる。実験は, エネルギー密度が $10^{6} \mathrm{~J} / \mathrm{m}^{2} \sim 2 \times 10^{6} \mathrm{~J} / \mathrm{m}^{2}$ あたりになると, 5 〜10shot以上エネルギーを重㸚わせた結果であり,その 時のレーザーの強度は, エネルギー密度が $2 \times 10^{4} \mathrm{~J} / \mathrm{m}^{2}$ の場 合のレーザーの強度の100倍あるのではない.エネルギー 密度が $2 \times 10^{6} \mathrm{~J} / \mathrm{m}^{2}$ の場合のシミュレーションでのレーザー

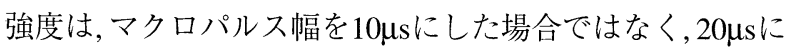
した場合の方が,より実験でのレーザーの強度に近い, と 考えられる.エネルギー密度が $2 \times 10^{6} \mathrm{~J} / \mathrm{m}^{2}$ の場合のシミュ レーション結果と実験結果を比較する場合, シミュレー

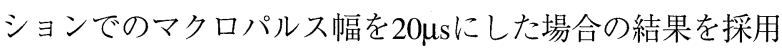
する方が,より妥当であろう。よって, 照射エネルギー密 度が $2 \times 10^{4} \mathrm{~J} / \mathrm{m}^{2} \sim 2 \times 10^{6} \mathrm{~J} / \mathrm{m}^{2}$ あたりまで,シミュレーショ ン結果と実駼結果は, 非常に良い一致を示している, と結

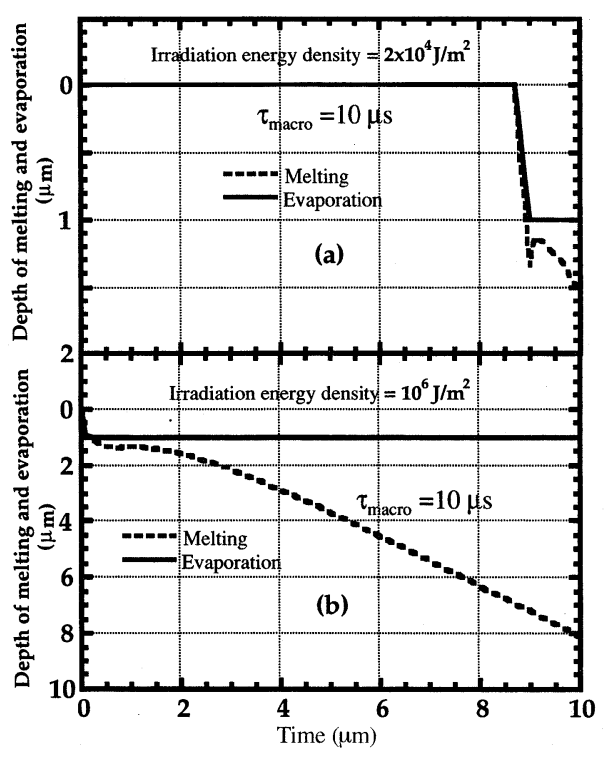

Fig.9 Time evolution of depth of melting and evaporation of $\mathrm{Fe}_{3} \mathrm{O}_{4}(1 \mu \mathrm{m}$ thickness $)$ and SUS304. a) Irradiation energy density is $2 \times 10^{4} \mathrm{~J} / \mathrm{m}^{2}$; b) Irradiation energy density is $10^{6} \mathrm{~J} / \mathrm{m}^{2}$.

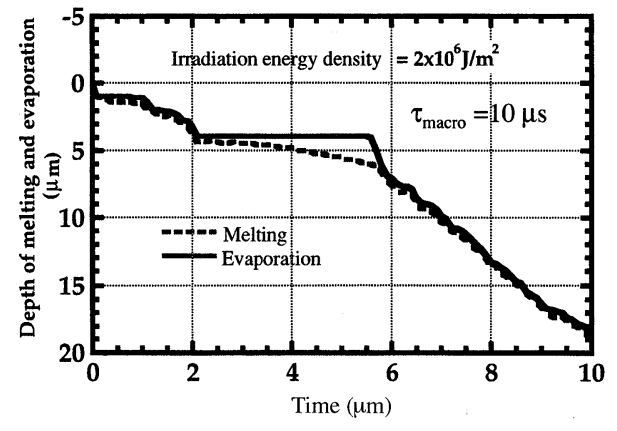

Fig.10 Time evolution of depth of melting and evaporation of $\mathrm{Fe}_{3} \mathrm{O}_{4}(1 \mu \mathrm{m}$ thickness) and SUS304 for the case of irradiation energy density is $2 \times 10^{6} \mathrm{~J} / \mathrm{m}^{2}$.

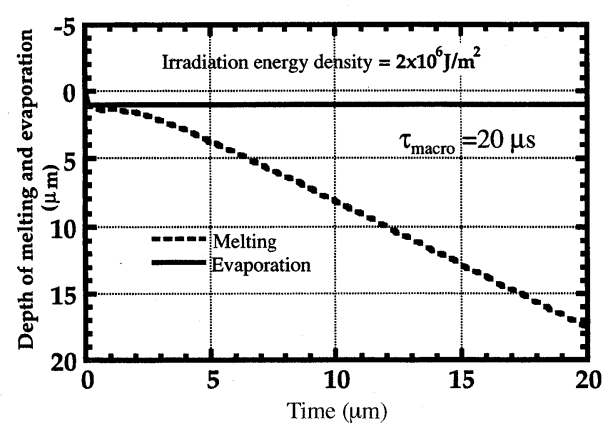

Fig.11 The same as Fig. 10 except that macro pulse width is $20 \mu \mathrm{s}$.

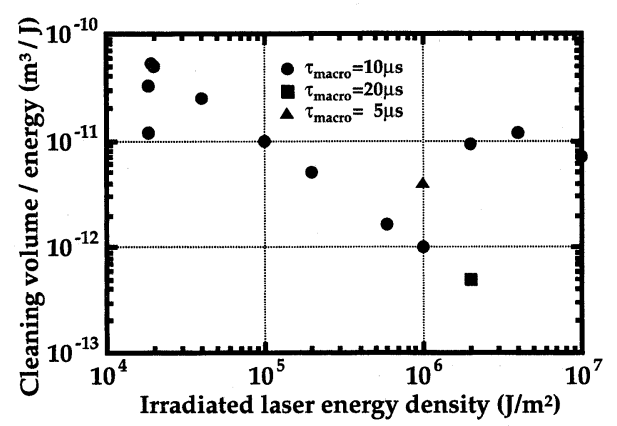

Fig.12 Cleaning volume per unit energy as irradiated laser energy density.

論できる。

\section{5. 結 論}

以上のことより,本シミュレーションコードは, 除染現 象の解析にあたり,その指針となり得ることが示された。 今後シミュレーションにより,レーザーの波形, パルス幅 等の最適化を行う予定である。

\section{参考文献}

1）レーザー学会編：レーザープロセッシング（日経技術図書, 1990).

2) レーザー学会学術講演会第15回年次大会 20aV6 (1995) p.191.

3）日本原子力学会 春の年会 N27（1996）p.691.

4) S. I. Anisimov and V. A. Khoklov: Instabilities in Laser-Matter Interaction CRC Press (1995).

5）日本化学会編：化学便覽基礎編II（丸善, 1975). 